\title{
BMJ Open Prevalence and trend of dyslipidaemia from 1996 to 2006 among normal and overweight adolescents in Taiwan
}

\author{
Philip Kuo, ${ }^{1}$ Jhu-Ting Syu, ${ }^{2}$ Isabel Lin Tzou, ${ }^{3}$ Pi-Yun Chen, ${ }^{4}$ Hsiu-Yueh Su, ${ }^{5}$ \\ Nain-Feng $\mathrm{Chu}^{6,7,8}$
}

To cite: Kuo P, Syu J-T, Tzou IL, et al. Prevalence and trend of dyslipidaemia from 1996 to 2006 among normal and overweight adolescents in Taiwan. BMJ Open 2014;4: e003800. doi:10.1136/ bmjopen-2013-003800

- Prepublication history for this paper is available online. To view these files please visit the journal online (http://dx.doi.org/10.1136/ bmjopen-2013-003800).

Received 15 August 2013 Revised 27 December 2013 Accepted 10 January 2014

CrossMark

For numbered affiliations see end of article.

Correspondence to Professor Nain-Feng Chu; chuepi@ndmctsgh.edu.tw

\section{ABSTRACT}

Objectives: To evaluate the trend of dyslipidaemia from 1996 to 2006 and examine its relationship with weight status among adolescents in Taiwan.

Design: 2 cross-sectional surveys were conducted in 1996 and 2006.

Setting: The junior high schools in Taipei.

Participants: After multistage sampling, total of 1500 and 1283 junior high school students were chosen in 1996 and 2006. After excluding missing data, a total of 1353 (676 boys and 677 girls) and 1203 (585 boys and 618 girls) children were included in the final analyses in 1996 and 2006.

Outcome measures: Anthropometric measures as body height and weight were measured, and body mass index (BMI) was calculated. Blood lipid profiles as total cholesterol, triglyceride, high-density lipoprotein cholesterol (HDL-C) and low-density lipoprotein cholesterol were measured.

Results: From 1996 to 2006, the prevalence of dyslipidaemia and hypercholesterolaemia significantly increased from $13 \%(95 \% \mathrm{Cl} 11.3 \%$ to $15.0 \%)$ to $22.3 \%(95 \% \mathrm{Cl} 20.0 \%$ to $24.7 \%)$ and $6.2 \%(95 \% \mathrm{Cl}$ $5.0 \%$ to $7.6 \%)$ to $13.8 \%(95 \% \mathrm{Cl} 11.9 \%$ to $15.9 \%)$, respectively. The prevalence of hypertriglyceridaemia and low HDL-C dyslipidaemia increased from $3 \%$ $(95 \% \mathrm{Cl} 1.8 \%$ to $4.5 \%)$ to $4.3 \%(95 \% \mathrm{Cl} 2.8 \%$ to $6.2 \%$ ) and $6.5 \%(95 \% \mathrm{Cl} 4.8 \%$ to $8.6 \%)$ to $11.6 \%$ $(95 \% \mathrm{Cl} 9.1 \%$ to $14.5 \%)$, with significance seen only in boys. When compared with normal weight participants, overweight boys and girls faced a 2 -fold and 1.6-fold increased risk of dyslipidaemia, respectively, in the 2006 study. The increased risk of low HDL-C dyslipidaemia for overweight participants was 2.6-fold and 7.2-fold in boys and girls,

respectively. In 2006, each unit increment of BMI was associated with $28 \%, 13 \%$ and $13 \%$ risk of hypertriglyceridaemia, low HDL-C and dyslipidaemia for boys, and $25 \%$ risk of low HDL-C dyslipidaemia in girls.

Conclusions: The prevalence of dyslipidaemia had increased significantly for boys and girls in normal weight and overweight adolescents. Early screening of dyslipidaemia and weight intervention programmes in adolescents will be the key to prevent dyslipidaemia and cardiovascular-related comorbidities.

\section{Strengths and limitations of this study}

- Repeat cross-sectional survey conducted in 1996 and 2006 with sufficient sample size to evaluate the trend of dyslipidaemia among adolescents.

- Demonstrates the detailed characteristics of lipid profiles (including total cholesterol, triglyceride, high-density lipoprotein cholesterol and low-density lipoprotein cholesterol) among adolescents.

- Provide information regarding the trend and prevalence of different definition of dyslipidaemia among normal and overweight adolescents.

- Analyses different models for adjusting the potential confounders such as age, gender, cigarette smoking, alcohol intake and puberty status and year trend.

- Dietary and physical activity information collected and analysed were inappropriate due to limitations of instrument.

\section{INTRODUCTION}

Cardiovascular disease (CVD) is the leading cause of death worldwide and accounts for $30 \%$ of all global deaths. ${ }^{1}$ The WHO predicts that, by 2030, CVD will account for 23.3 million deaths compared with the 17.3 million deaths seen in $2008 .^{1}$

CVD is a group of disorders which affect the heart and/or the blood vessels. Disorders include coronary heart disease, cerebrovascular disease, peripheral arterial disease, rheumatic heart disease, congenital heart disease, deep vein thrombosis, pulmonary embolisms, etc. ${ }^{1}$ In addition to age and gender, unhealthy diets, physical inactivity, hyperglycaemia, cigarette smoking, dyslipidaemia, hypertension, type 2 diabetes and obesity have been identified as risk factors for the prediction of development of CVD. $^{1-3}$

Childhood obesity has also been identified as one of the most important risk factors of developing cardiometabolic diseases such as dyslipidaemia, insulin resistance and hypertension. ${ }^{4-7}$ The trends of obesity and 
dyslipidaemia have been studied extensively in Western societies; however, there is a lack of data pertaining to adiposity and abnormal lipid profiles in the Taiwanese population. ${ }^{8}$ The research into the relationship between children with abnormal blood lipid profiles and CVD is important to mitigating the problem of childhood obesity.

In Taiwan, the prevalence of obesity also continues to increase among adults and children, which may be attributed to the steadily increasing availability of a high-fat, highcalorie diet as well as a more sedentary and physically inactive lifestyle. ${ }^{9-12}$ In recent 20 years, there was also an increase in prevalence rate of overweight and obesity among Taiwanese adolescents (12-15 years). ${ }^{10} \quad{ }^{13}$ The trend of overweight has almost tripled over two decades, from $3 \%$ to $12 \%$ from the years $1970-1988 .{ }^{13} 14$

The purpose of this study was to evaluate the recent trend of dyslipidaemia and its relation to anthropometric and biochemical measurements in order to predict the future prevalence rate of CVD among adolescents in Taiwan.

\section{MATERIALS AND METHODS}

Study population and design

The Taipei Children Heart Studies were a series of epidemiological surveys conducted during the past two decades which investigated CVD risk factors among school children living in Taipei, Taiwan. ${ }^{15}$ In 1996 and 2006, two cross-sectional surveys were conducted in Taipei among junior high school students in order to ascertain a representative distribution of demographic, lifestyle and biochemical characteristics and CVD risk factors. During 1996, 101000 junior high school students were enrolled in 47 large schools $(\geq 40$ classes per school) and 28000 students in 38 small schools $(<40$ classes per school). After multistage sampling, random selection of seven large schools and three small schools, with six classes sampled per school, a total of 1500 junior high school students were chosen for this epidemiological survey in 1996. The same techniques were used for the multistage sampling method conducted in 2006 and a total of 1283 students were selected. After factoring in study power and excluding missing data, a total of 1353 ( 676 boys and 677 girls) and 1203 (585 boys and 618 girls) children were included in the final analyses in 1996 and 2006.

All participating children completed a structured questionnaire detailing their gender, age, puberty development and lifestyle characteristics, such as cigarette smoking and alcohol consumption. The questionnaires were submitted to an expert panel with each question tested for test-retest reliability and validity. Informed consent was obtained from the parents and children.

\section{Anthropometric, blood pressure and lipid measurements}

Body weight (BW) was measured to an accuracy of $0.1 \mathrm{~kg}$ using a standard beam balance scale for participants in barefoot and wearing light indoor clothing. Body height was recorded to the nearest $0.5 \mathrm{~cm}$ using a stadiometer. Waist circumference (WC) was measured to the nearest $0.1 \mathrm{~cm}$ at the midpoint between the inferior margin of the last rib and the iliac crest. Body mass index (BMI) was calculated using $\mathrm{BW}(\mathrm{kg})$ divided by the square of their height $\left(\mathrm{m}^{2}\right)$.

For the systolic (SBP) and diastolic blood pressure (DBP) measurements, participants were asked to rest for 10 min in a sitting position before their BP was taken on their right arm using appropriate cuff sizes. The first and fifth Korotkoff sounds were recorded for the SBP and DBP, respectively. The BP was measured again after a 5 min resting period and the average was used in the analyses. In between the two BP measures, heart rate was measured for $1 \mathrm{~min}$.

A $12 \mathrm{~h}$ fasting blood sample was taken from students who maintained their usual dietary pattern within the past 3 days. The plasma glucose concentrations were analysed immediately after blood sampling and other assays were performed within a 2-week period of the sampling. Plasma glucose levels were measured using a standard method, serum total cholesterol (TC) using an esterase oxidase method, triacylglycerol using an enzymatic procedure and high-density lipoprotein (HDL) cholesterol using an enzymatic method with magnesium precipitation with the Synchron CX5 analyzer (Beckman Instruments, Palo Alto, California, USA) ${ }^{16-20}$ Since all samples were collected after a $12 \mathrm{~h}$ fast and no triacylglycerol concentrations exceeded $4.52 \mathrm{mmol} / \mathrm{L}$ ( $400 \mathrm{mg}$ / dL), we used Friedewald's formula to calculate the lowdensity lipoprotein (LDL) cholesterol: LDL cholesterol $=(\mathrm{TC}-\mathrm{HDL}$ cholesterol $)-($ triacylglycerol $/ 5) .{ }^{21} \mathrm{We}$ also determined the ratio of total to HDL cholesterol (total: HDL cholesterol) for statistical purposes.

\section{Definition of overweight, obesity and abnormal lipid profiles}

The operational definition of overweight and obesity is determined by applying gender-specific and age-specific percentile cut-off points in a reference population (generally the 85th centile for overweight and 95th centile for obesity). Our study defined overweight and obesity as $\geq 85$ th centile value and $\geq$ the95th centile value of BMI, respectively, using gender-specific and age-specific criteria from childhood obesity expert panel of the Department of Health (DOH), Taiwan. ${ }^{22}$

The cut-offs for children for the abnormal lipid profiles were determined using guidelines from the American Heart Association (AHA). ${ }^{3}$ Hypercholesterolaemia and hypertriglyceridaemia were taken as cholesterol greater than $200 \mathrm{mg} / \mathrm{dL}$ and serum triglyceride (TG) greater than $150 \mathrm{mg} / \mathrm{dL}$, respectively. Low HDL dyslipidaemia was taken as serum HDL-C lower than $35 \mathrm{mg} / \mathrm{dL}$, and dyslipidaemia was taken as one or more of the above listed abnormal lipid profiles found in the participants. 


\section{Statistical analysis}

Continuous variables, anthropometric characteristics and lipid profiles with gender specification were described by sample means and SD. Age-adjusted means and SE were estimated using the general linear model (GLM). Categorical variables were expressed through frequency using percentages. To determine whether weight status was a predictor of dyslipidaemia, multivariate regression models were used to assess the association between dyslipidaemia and its subtypes with weight status. A two-tailed $p$ value less than 0.05 was considered statistically significant. All statistical analyses were conducted by the statistical package SAS V.9.0 (SAS Institute Inc, Cary, North Carolina, USA).

\section{RESULTS}

In the 1996 survey, a total of 1353 children (676 boys and 677 girls) with a mean age of 13.0 (range 12-14-year-olds) were included. After adjusting for age, mean $( \pm$ SE) TC was $151.6 \pm 1.1$ and $161.5 \pm 1.1 \mathrm{mg} / \mathrm{dL}$, TGs was $70.4 \pm 1.3$ and $77.2 \pm 1.3 \mathrm{mg} / \mathrm{dL}$, HDL-C was $53.7 \pm 0.5$ and 55.1 $\pm 0.5 \mathrm{mg} / \mathrm{dL}$ and LDL-C was $93.9 \pm 1.1$ and $102.1 \pm 1.1$ for boys and girls, respectively. In the 2006 survey, a total of 1203 children (585 boys and 618 girls) were included. After adjusting for age, mean $( \pm \mathrm{SE})$ TC was $164.1 \pm 1.2$ and $174.5 \pm 1.2 \mathrm{mg} / \mathrm{dL}$, TGs was $70.9 \pm 1.4$ and 72.1 $\pm 1.4 \mathrm{mg} / \mathrm{dL}$, HDL-C was $47.3 \pm 0.5$ and $51.5 \pm 0.5 \mathrm{mg} / \mathrm{dL}$ and LDL-C was $93.0 \pm 1.1$ and $97.0 \pm 1.1$ for boys and girls, respectively. The anthropometric data and lifestyle characteristics for boys and girls in the 1996 and 2006 studies are presented in table 1. Overall, the age-adjusted mean BW, BMI and WC for boys increased from 1996 to 2006 (all $\mathrm{p}<0.05$ ). However, the weight and BMI for girls slightly decreased in that same time period.

Table 2 shows the age-adjusted prevalence and secular trends of hypercholesterolaemia, hypertriglyceridaemia, low HDL dyslipidaemia and general dyslipidaemia

Table 1 General characteristics among study children between 1996 and 2006 in Taiwan

\begin{tabular}{|c|c|c|c|c|c|c|c|c|c|}
\hline \multirow[b]{2}{*}{ Boys } & \multicolumn{4}{|l|}{1996} & \multicolumn{4}{|l|}{2006} & \multirow[b]{2}{*}{ p Valuet } \\
\hline & $\begin{array}{l}\text { Mean } \pm S E^{*} \\
(n=676)\end{array}$ & 85th & 90th & 95th & $\begin{array}{l}\text { MeantSE* } \\
(n=585)\end{array}$ & 85th & 90th & 95th & \\
\hline Age (years) & $12.9 \pm 0.03$ & NA & NA & NA & $12.9 \pm 0.03$ & NA & NA & NA & \\
\hline Height (cm) & $161.9 \pm 0.3$ & 170.0 & 171.5 & 174.5 & $163.5 \pm 0.3$ & 172.5 & 174.0 & 176.7 & 0.230 \\
\hline Weight (kg) & $55.5 \pm 0.4$ & 67.5 & 71.5 & 78.0 & $58.0 \pm 0.5$ & 73.0 & 76.8 & 82.5 & 0.006 \\
\hline BMI $\left(\mathrm{kg} / \mathrm{m}^{2}\right)$ & $21.1 \pm 0.1$ & 25.2 & 26.5 & 28.7 & $21.6 \pm 0.2$ & 26.4 & 27.3 & 29.3 & 0.013 \\
\hline Waist (cm) & $68.3 \pm 0.3$ & 77.2 & 80.8 & 86.6 & $73.5 \pm 0.4$ & 85.0 & 88.0 & 92.0 & $<0.001$ \\
\hline $\mathrm{SBP}(\mathrm{mm} \mathrm{Hg})$ & $113.9 \pm 0.5$ & 127.0 & 130.5 & 135.0 & $117.8 \pm 0.5$ & 131.0 & 134.5 & 141.5 & 0.001 \\
\hline $\mathrm{DBP}(\mathrm{mm} \mathrm{Hg})$ & $67.6 \pm 0.4$ & 77.0 & 80.0 & 83.0 & $69.0 \pm 0.4$ & 79.0 & 81.5 & 86.5 & 0.093 \\
\hline Chol (mg/dL) & $151.6 \pm 1.1$ & 179.0 & 186.0 & 200.0 & $164.1 \pm 1.2$ & 192.0 & 202.0 & 213.0 & $<0.001$ \\
\hline TGs (mg/dL) & $70.4 \pm 1.3$ & 99.0 & 113.0 & 134.0 & $70.9 \pm 1.4$ & 101.0 & 118.0 & 145.0 & 0.464 \\
\hline $\mathrm{HDL}(\mathrm{mg} / \mathrm{dL})$ & $53.7 \pm 0.5$ & 67.0 & 70.0 & 77.0 & $47.3 \pm 0.5$ & 59.0 & 62.0 & 66.0 & $<0.001$ \\
\hline Glucose (mg/dL) & $93.4 \pm 0.3$ & 101.0 & 103.0 & 106.0 & $93.6 \pm 0.3$ & 100.0 & 102.0 & 105.0 & 0.556 \\
\hline LDL & $93.9 \pm 1.1$ & 118.56 & 126.83 & 140.50 & $93.00 \pm 1.08$ & 117.00 & 126.00 & 140.00 & 0.711 \\
\hline Non-HDL & $97.9 \pm 1.1$ & 123.00 & 131.00 & 145.00 & $116.80 \pm 1.13$ & 141.00 & 150.00 & 164.00 & $<0.001$ \\
\hline Chol/HDL & $2.97 \pm 0.03$ & 3.66 & 4.05 & 4.63 & $3.61 \pm 0.03$ & 4.49 & 4.80 & 5.25 & $<0.001$ \\
\hline TGs/HDL & $1.44 \pm 0.04$ & 2.15 & 2.44 & 3.23 & $1.66 \pm 0.04$ & 2.49 & 2.94 & 4.03 & 0.002 \\
\hline Girls & $(n=677)$ & & & & $(n=618)$ & & & & \\
\hline Age (years) & $13.0 \pm 0.03$ & NA & NA & NA & $12.9 \pm 0.03$ & NA & NA & NA & \\
\hline Height $(\mathrm{cm})$ & $156.3 \pm 0.3$ & 162.0 & 163.5 & 165.0 & $156.9 \pm 0.3$ & 162.5 & 163.5 & 166.0 & 0.379 \\
\hline Weight (kg) & $50.8 \pm 0.4$ & 59.0 & 62.5 & 69.5 & $50.6 \pm 0.5$ & 59.6 & 64.1 & 69.4 & 0.027 \\
\hline BMI $\left(\mathrm{kg} / \mathrm{m}^{2}\right)$ & $20.7 \pm 0.1$ & 24.0 & 25.2 & 27.4 & $20.5 \pm 0.2$ & 24.0 & 25.2 & 27.6 & 0.005 \\
\hline Waist $(\mathrm{cm})$ & $63.2 \pm 0.3$ & 68.6 & 72.3 & 76.9 & $69.2 \pm 0.4$ & 77.5 & 80.5 & 85.0 & $<0.001$ \\
\hline $\mathrm{SBP}(\mathrm{mm} \mathrm{Hg})$ & $104.4 \pm 0.5$ & 117.0 & 120.0 & 126.0 & $111.2 \pm 0.5$ & 124.0 & 127.5 & 133.0 & $<0.001$ \\
\hline $\mathrm{DBP}(\mathrm{mm} \mathrm{Hg})$ & $67.7 \pm 0.4$ & 77.5 & 80.0 & 84.0 & $69.7 \pm 0.4$ & 79.0 & 81.5 & 87.0 & $<0.001$ \\
\hline Chol (mg/dL) & $161.5 \pm 1.1$ & 187.0 & 195.0 & 209.0 & $174.5 \pm 1.2$ & 204.0 & 212.0 & 227.0 & $<0.001$ \\
\hline TGs (mg/dL) & $77.2 \pm 1.3$ & 107.0 & 118.0 & 140.0 & $72.1 \pm 1.4$ & 102.0 & 117.0 & 131.0 & 0.003 \\
\hline $\mathrm{HDL}(\mathrm{mg} / \mathrm{dL})$ & $55.1 \pm 0.5$ & 68.0 & 71.0 & 76.0 & $51.5 \pm 0.5$ & 63.0 & 66.0 & 70.0 & $<0.001$ \\
\hline Glucose (mg/dL) & $91.6 \pm 0.3$ & 99.0 & 101.0 & 104.0 & $91.6 \pm 0.3$ & 99.0 & 101.0 & 103.0 & 0.757 \\
\hline LDL & $102.1 \pm 1.1$ & 129.17 & 134.78 & 145.78 & $97.02 \pm 1.05$ & 125.00 & 131.00 & 143.00 & $<0.001$ \\
\hline Non-HDL & $106.4 \pm 1.1$ & 133.00 & 140.00 & 151.00 & $122.95 \pm 1.10$ & 148.00 & 159.00 & 172.00 & $<0.001$ \\
\hline Chol/HDL & $3.04 \pm 0.03$ & 3.85 & 4.00 & 4.35 & $3.49 \pm 0.03$ & 4.14 & 4.42 & 4.85 & $<0.001$ \\
\hline TGs/HDL & $1.51 \pm 0.04$ & 2.21 & 2.56 & 3.02 & $1.51 \pm 0.04$ & 2.28 & 2.59 & 3.28 & 0.739 \\
\hline
\end{tabular}

${ }^{*}$ Age-adjusted mean \pm SE.

tp Value when compared with the same gender group for 1996 and 2006 using GLM after adjusting for age, cigarette smoking, alcohol drinking and puberty status.

BMI, body mass index; Chol, total cholesterol; DBP, diastolic blood pressure; GLM, general linear model; HDL, high-density lipoprotein-cholesterol; LDL, low-density lipoprotein; SBP, systolic blood pressure; TGs, triglycerides. 
Table 2 Prevalence and secular trends of abnormal lipid profiles among children between year 1996 and 2006 in Taiwan

\begin{tabular}{|c|c|c|c|c|c|}
\hline & \multicolumn{2}{|c|}{$1996(n=1353)$} & \multicolumn{2}{|c|}{$2006(n=1203)$} & \multirow[b]{2}{*}{ p Value* } \\
\hline & $\overline{\mathbf{N}}$ & Per cent $(95 \% \mathrm{Cl}) \dagger$ & $\overline{\mathbf{N}}$ & Per cent $(95 \% \mathrm{Cl}) \dagger$ & \\
\hline Hypercholesterolaemiał & 84 & 6.21 (4.98 to 7.63$)$ & 166 & $13.8(11.90$ to 15.88$)$ & $<0.001$ \\
\hline Boys & 33 & 4.88 (3.38 to 6.79$)$ & 62 & $10.6(8.22$ to 13.38$)$ & $<0.001$ \\
\hline Girls & 51 & 7.53 (5.66 to 9.79$)$ & 104 & 16.83 (13.96 to 20.02$)$ & $<0.001$ \\
\hline Hypertriglyceridaemia§ & 42 & $3.10(2.25$ to 4.17$)$ & 39 & 3.24 (2.32 to 4.44$)$ & 0.843 \\
\hline Boys & 20 & 2.96 (1.82 to 4.53$)$ & 25 & 4.27 (2.78 to 6.24$)$ & 0.209 \\
\hline Girls & 22 & 3.25 (2.05 to 4.88$)$ & 14 & 2.27 (1.24 to 3.77$)$ & 0.282 \\
\hline Low HDL dyslipidaemia† & 63 & 4.66 (3.60 to 5.92$)$ & 88 & 7.32 (5.91 to 8.93$)$ & 0.004 \\
\hline Boys & 44 & 6.51 (4.77 to 8.64$)$ & 68 & 11.62 (9.14 to 14.50$)$ & 0.002 \\
\hline Girls & 19 & 2.81 (1.70 to 4.35$)$ & 20 & 3.24 (1.99 to 4.95$)$ & 0.651 \\
\hline Dyslipidaemiaๆ & 176 & 13.01 (11.26 to 14.92$)$ & 268 & 22.28 (19.95 to 24.74$)$ & $<0.001$ \\
\hline Boys & 91 & 13.46 (10.98 to 16.27$)$ & 138 & 23.59 (20.20 to 27.24$)$ & $<0.001$ \\
\hline Girls & 85 & $12.56(10.15$ to 15.29$)$ & 130 & 21.04 (17.89 to 24.46$)$ & $<0.001$ \\
\hline
\end{tabular}

${ }^{*} \mathrm{p}$ Value when compared with 1996.

†Low HDL dyslipidaemia is taken as serum HDL-C of age-specific, gender-specific and height-specific strata.

†Hypercholesterolaemia is taken as cholesterol greater than or equal to the 90th centile of age-specific, gender-specific and height-specific strata.

§Hypertriglyceridaemia is taken as serum triglyceride greater than or equal to the 95th centile of age-specific, gender-specific and height-specific strata.

IDyslipidaemia is taken as serum cholesterol, TGs, HDL-C of age-specific, gender-specific and height-specific strata.

HDL, high-density lipoprotein; HDL-C, HDL-cholesterol; TGs, triglycerides.

among children in Taiwan in 1996 and 2006. For both genders, the prevalence of hypercholesterolaemia and general dyslipidaemia increased from 1996 to 2006. The prevalence of hypertriglyceridaemia and low HDL dyslipidaemia also increased, but only in boys. The prevalence of dyslipidaemia and hypercholesterolaemia increased from $13 \%(95 \% \mathrm{CI}, 11.3 \%$ to $15.0 \%)$ to $22.3 \%$ (95\% CI $20.0 \%$ to $24.7 \%$ ) and $6.2 \%$ (95\% CI $5.0 \%$ to $7.6 \%$ ) to $13.8 \%$ (95\% CI $11.9 \%$ to $15.9 \%$ ), in boys and girls, respectively. Hypertriglyceridaemia and low HDL dyslipidaemia increased from $3 \% \quad(95 \%$ CI $1.8 \%$ to $4.5 \%$ ) to $4.3 \%$ (95\% CI $2.8 \%$ to $6.2 \%$ ) and $6.5 \%(95 \%$ CI $4.8 \%$ to $8.6 \%$ ) to $11.6 \%$ (95\% CI $9.1 \%$ to $14.5 \%$ ), in boys and girls, respectively, with significance seen only in boys (see figure 1).

Table 3 demonstrates the age-adjusted prevalence of hypercholesterolaemia, hypertriglyceridaemia, low HDL dyslipidaemia and general dyslipidaemia separated by weight status in 1996 and 2006. The prevalence of all types of dyslipidaemia increased from 1996 to 2006 in
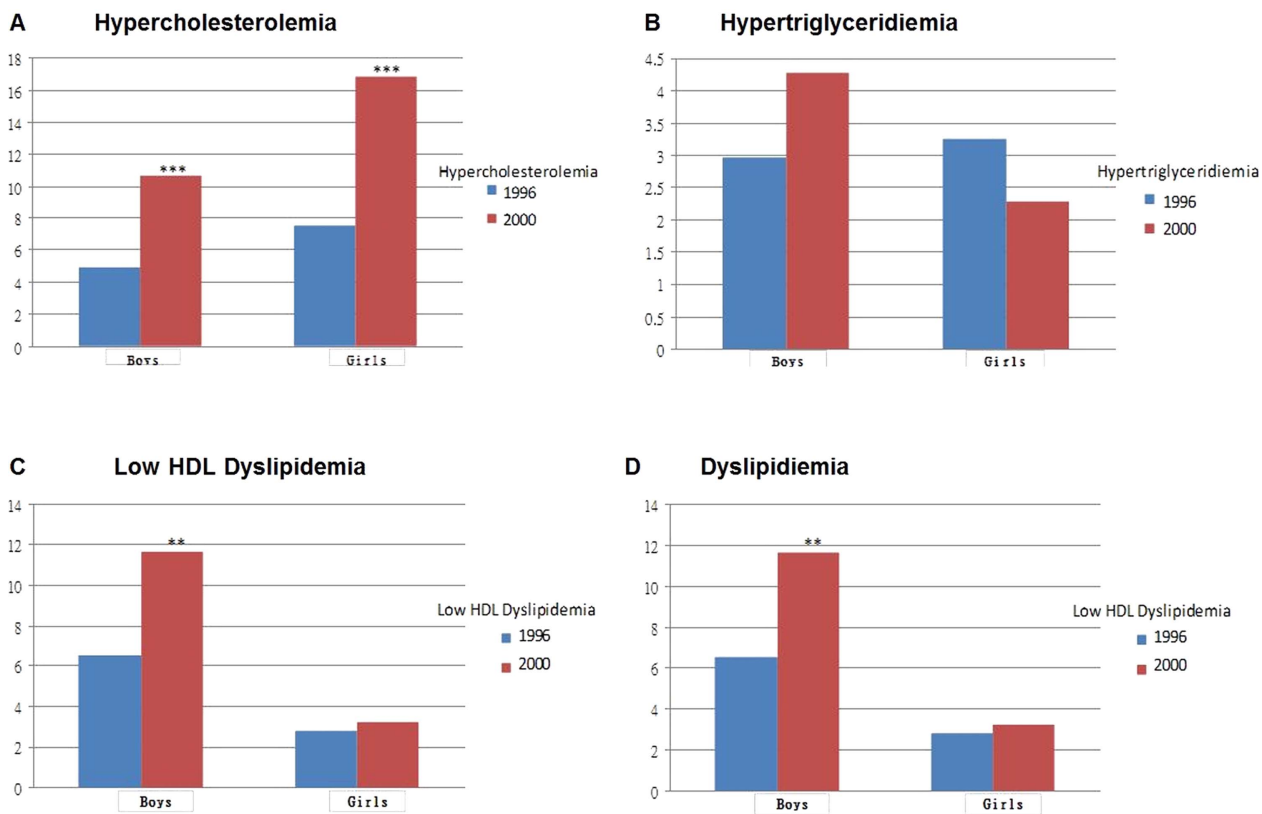

Figure 1 Prevalence and secular trends of abnormal lipid profiles among children between year 1996 and 2006 in Taiwan. HDL, high-density lipoprotein. 
Table 3 Prevalence and secular trends of abnormal blood lipid profiles among different weight status children between 1996 and 2006 in Taiwan

\begin{tabular}{|c|c|c|c|c|c|c|c|}
\hline & \multicolumn{4}{|c|}{1996} & \multicolumn{3}{|c|}{2006} \\
\hline & $\overline{\mathbf{N}}$ & Per cent ${ }^{\star} \ddagger \ddagger$ & p Valuet & p Value & $\overline{\mathbf{N}}$ & Per cent ${ }^{\star} \neq \ddagger$ & p Value \\
\hline \multicolumn{8}{|c|}{ Hypercholesterolaemia§ } \\
\hline \multicolumn{8}{|l|}{ Boys } \\
\hline Normal weight & 22 & 4.76 & 0.006 & \multirow[t]{2}{*}{0.832} & 35 & 9.67 & \multirow[t]{2}{*}{0.352} \\
\hline Overweight & 11 & 5.14 & 0.010 & & 27 & 12.11 & \\
\hline \multicolumn{8}{|l|}{ Girls } \\
\hline Normal weight & 39 & 7.62 & $<0.001$ & \multirow[t]{2}{*}{0.884} & 76 & 16.27 & \multirow[t]{2}{*}{0.517} \\
\hline Overweight & 12 & 7.27 & 0.003 & & 28 & 18.54 & \\
\hline \multicolumn{8}{|c|}{ Hypertriglyceridaemia** $^{*}$} \\
\hline \multicolumn{8}{|l|}{ Boys } \\
\hline Normal weight & 2 & 0.43 & 0.468 & \multirow[t]{2}{*}{$<0.001$} & 3 & 0.83 & \multirow[t]{2}{*}{$<0.001$} \\
\hline Overweight & 18 & 8.41 & 0.598 & & 22 & 9.87 & \\
\hline \multicolumn{8}{|l|}{ Girls } \\
\hline Normal weight & 16 & 3.13 & 0.093 & \multirow[t]{2}{*}{0.747} & 7 & 1.50 & \multirow[t]{2}{*}{0.024} \\
\hline Overweightๆ & 6 & 3.64 & 0.655 & & 7 & 4.64 & \\
\hline \multicolumn{8}{|c|}{ Low HDL-C dyslipidaemia†† } \\
\hline \multicolumn{8}{|c|}{ Boys } \\
\hline Normal weight & 18 & 3.90 & 0.037 & \multirow[t]{2}{*}{$<0.001$} & 26 & 7.18 & \multirow[t]{2}{*}{$<0.001$} \\
\hline Overweightๆ & 26 & 12.15 & 0.054 & & 42 & 18.83 & \\
\hline \multicolumn{8}{|l|}{ Girls } \\
\hline Normal weight & 10 & 1.95 & 0.410 & \multirow[t]{2}{*}{0.018} & 6 & 1.28 & \multirow[t]{2}{*}{$<0.001$} \\
\hline Overweight & 9 & 5.45 & 0.192 & & 14 & 9.27 & \\
\hline \multicolumn{8}{|l|}{ Dyslipidaemia* } \\
\hline \multicolumn{8}{|l|}{ Boys } \\
\hline Normal weight & 42 & 9.09 & 0.001 & \multirow[t]{2}{*}{$<0.001$} & 62 & 17.13 & \multirow[t]{2}{*}{$<0.001$} \\
\hline Overweight & 49 & 22.90 & 0.010 & & 76 & 34.08 & \\
\hline \multicolumn{8}{|l|}{ Girls } \\
\hline Normal weight & 61 & 11.91 & 0.005 & \multirow[t]{2}{*}{0.375} & 86 & 18.42 & \multirow[t]{2}{*}{0.005} \\
\hline Overweight & 24 & 14.55 & 0.002 & & 44 & 29.14 & \\
\hline 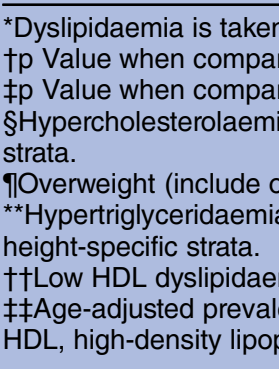 & $\begin{array}{l}\text { erum } \\
\text { ith } 20 \\
\text { ith ov } \\
\text { aken } \\
\text { y) is c } \\
\text { aken a } \\
\text { taker }\end{array}$ & $\begin{array}{l}\text { sterol, TGs, HDL } \\
\text { ght (after Bonferr } \\
\text { olesterol greater } \\
\text { d as the overwei } \\
\text { um triglyceride g } \\
\text { serum HDL-C of }\end{array}$ & $\begin{array}{l}\text { age-specific } \\
\text { orrection: } \alpha \text { le } \\
\text { or equal to th } \\
\text { ad obese stat } \\
\text { than or eque } \\
\text { pecific, gend } \\
\text { triglycerides. }\end{array}$ & $\begin{array}{l}\text { der-specific a } \\
.05 / 8=0.006 \\
\text { centile of a } \\
\text { teria of childr } \\
\text { he } 95 \text { th centi } \\
\text { ecific and hei }\end{array}$ & $\begin{array}{l}\text { ecific, } \\
\text { Taiwe } \\
\text { age-sp } \\
\text { Decific }\end{array}$ & ic strata. & specific \\
\hline
\end{tabular}

both sexes and weight statuses, except for hypertriglyceridaemia and low HDL-C dyslipidaemia for normal weight girls. When compared with normal weight participants, overweight boys and girls faced a 2-fold and 1.6-fold increased risk of dyslipidaemia, respectively, in the 2006 study. For hypercholesterolaemia and hypertriglyceridaemia, overweight boys had 1.3-fold and 12-fold increased risk, respectively, compared with normal weight boys. The increased risk of low HDL-C dyslipidaemia for overweight participants was 2.6-fold and 7.2-fold in boys and girls, respectively.

Table 4 presents the logistic regression analysis of year trend, BMI and WC on hypercholesterolaemia, hypertriglyceridaemia, low HDL dyslipidaemia and general dyslipidaemia with gender specification after combined 1996 and 2006 data. In model 1, we found that year 2006 had a higher OR for hypercholesterolaemia, low HDL-C dyslipidaemia and dyslipidaemia (ORs was 2.310, 1.889 and 1.985, respectively) when compared with year 1996 . Furthermore, each unit increment of BMI was associated with $28 \%, 14 \%$ and $14 \%$ increasing risk of hypertriglyceridaemia, low HDL-C dyslipidaemia and dyslipidaemia for boys, and 20\% increasing risk of low HDL-C dyslipidaemia for girls. Each centimetre increase in WC was associated with $9 \%$ increased risk of low HDL dyslipidaemia in girls. Similar results were seen in model 2; increment of BMI and WC were as associated with abnormal blood lipid profiles after adjusting for age, cigarette smoking, alcohol consumption, puberty status and time trend.

\section{DISCUSSION}

The present study represents the analysis of secular trends in dyslipidaemia in Taiwanese children from 1996 
Table 4 Logistic regression analyses of BMI and WC on abnormal blood lipid profiles among children with gender specification in Taiwan (combined 1996 and 2006 data)

\begin{tabular}{|c|c|c|c|c|}
\hline & \multicolumn{2}{|c|}{ Model 1} & \multicolumn{2}{|c|}{ Model 2} \\
\hline & $\overline{\text { OR }}$ & $95 \% \mathrm{Cl}$ & $\overline{\text { OR }}$ & $95 \% \mathrm{Cl}$ \\
\hline \multicolumn{5}{|l|}{ Hypercholesterolaemia* } \\
\hline \multicolumn{5}{|l|}{ Boys } \\
\hline Year 2006 vs1996 & 2.310 & 1.491 to 3.579 & - & - \\
\hline $\mathrm{BMI}$ & 1.044 & 0.994 to 1.096 & 1.039 & 0.988 to 1.092 \\
\hline WC & 1.025 & 1.006 to 1.045 & 1.017 & 0.996 to 1.038 \\
\hline \multicolumn{5}{|l|}{ Girls } \\
\hline Year 2006 vs1996 & 2.484 & 1.742 to 3.541 & - & - \\
\hline BMI & 1.030 & 0.984 to 1.078 & 1.027 & 0.980 to 1.077 \\
\hline WC & 1.032 & 1.013 to 1.051 & 1.015 & 0.994 to 1.036 \\
\hline \multicolumn{5}{|l|}{ Hypertriglyceridaemia† } \\
\hline \multicolumn{5}{|l|}{ Boys } \\
\hline Year 2006 vs1996 & 1.464 & 0.805 to 2.665 & - & - \\
\hline BMI & 1.284 & 1.205 to 1.369 & 1.299 & 1.217 to 1.388 \\
\hline WC & 1.102 & 1.074 to 1.131 & 1.109 & 1.079 to 1.139 \\
\hline \multicolumn{5}{|l|}{ Girls } \\
\hline Year 2006 vs1996 & 0.690 & 0.350 to 1.361 & - & - \\
\hline BMI & 1.078 & 0.994 to 1.168 & 1.079 & 0.993 to 1.173 \\
\hline WC & 1.023 & 0.987 to 1.061 & 1.035 & 0.997 to 1.075 \\
\hline \multicolumn{5}{|c|}{ Low HDL-C dyslipidaemiał } \\
\hline \multicolumn{5}{|l|}{ Boys } \\
\hline Year 2006 vs1996 & 1.889 & 1.271 to 2.809 & - & - \\
\hline BMI & 1.135 & 1.087 to 1.184 & 1.134 & 1.086 to 1.185 \\
\hline WC & 1.054 & 1.036 to 1.072 & 1.051 & 1.032 to 1.070 \\
\hline \multicolumn{5}{|l|}{ Girls } \\
\hline Year 2006 vs1996 & 1.158 & 0.612 to 2.191 & - & - \\
\hline BMI & 1.201 & 1.124 to 1.283 & 1.208 & 1.130 to 1.292 \\
\hline WC & 1.087 & 1.055 to 1.120 & 1.094 & 1.060 to 1.129 \\
\hline \multicolumn{5}{|l|}{ Dyslipidaemia§ } \\
\hline \multicolumn{5}{|l|}{ Boys } \\
\hline Year 2006 vs1996 & 1.985 & 1.482 to 2.657 & - & - \\
\hline BMI & 1.135 & 1.097 to 1.174 & 1.135 & 1.096 to 1.175 \\
\hline WC & 1.056 & 1.041 to 1.070 & 1.052 & 1.037 to 1.067 \\
\hline \multicolumn{5}{|l|}{ Girls } \\
\hline Year 2006 vs1996 & 1.855 & 1.377 to 2.501 & - & - \\
\hline BMI & 1.070 & 1.030 to 1.113 & 1.071 & 1.029 to 1.114 \\
\hline WC & 1.043 & 1.026 to 1.061 & 1.034 & 1.016 to 1.053 \\
\hline \multicolumn{5}{|c|}{$\begin{array}{l}\left.\text { Model 1: univariate analyses for year } 2006 \text { vs } 1996 \text {, increase of one unit BMI or WC (BMI: } 1 \mathrm{~kg} / \mathrm{m}^{2} ; \mathrm{WC}: 1 \mathrm{~cm}\right) \text {. } \\
\text { Model 2: further adjusting for age, cigarette smoking, alcohol drinking, puberty status and year trend. } \\
\text { *Hypercholesterolaemia is taken as cholesterol greater than or equal to the } 90 \text { th centile of age-specific, gender-specific and height-specific } \\
\text { strata. } \\
\text { †Hypertriglyceridaemia is taken as serum triglyceride greater than or equal to the } 95 \text { th centile of age-specific, gender-specific and } \\
\text { height-specific strata. } \\
\text { fLow HDL dyslipidaemia is taken as serum HDL-C of age-specific, gender-specific and height-specific strata. } \\
\text { §Dyslipidaemia is taken as serum cholesterol, TGs, HDL-C of age-specific, gender-specific and height-specific strata. } \\
\text { BMl, body mass index; HDL, high-density lipoprotein; HDL-C, HDL-cholesterol; TGs, triglycerides; WC, waist circumference. }\end{array}$} \\
\hline
\end{tabular}

to 2006. Examination of the anthropometric and lipid statuses over the 10-year period found an increase in hypercholesterolaemia and dyslipidaemia in both sexes and an increase in low HDL dyslipidaemia in boys. Prevalence of hypertriglyceridaemia and low HDL dyslipidaemia increased in boys, but not in girls. BMI was associated with hypertriglyceridaemia, low HDL dyslipidaemia and dyslipidaemia in boys and low HDL dyslipidaemia in girls. WC showed similar associations, however, to a much lower degree.
There are several limitations to be noted in the calculation and interpretation of our anthropometric results. First, the cross-sectional study design may have yielded biased results; however, the large sample size should make up for any students who had any medical history or treatments. Second, the measurement bias of the cut-off points of BMI in the definition of overweight and obese that may have biased this association between adiposity and lipid characteristics. Using a universal BMI cut-off point for overweight and obesity may not be 
appropriate for comparing the prevalence of obesity and its association with abnormal lipid profiles among different ethnic groups. Third, we used GLM and multivariate regression models to examine the prevalence of dyslipidaemia which may be associated with somewhat biased results. Finally, we did not assess the different factors which may have impacted the trend such as diet, puberty, alcohol or smoking habits. Further assessment of environmental factors, such as nutritional condition, dietary and physical activity habits, may have garnered greater insight on the relationship among those factors and dyslipidaemia.

The increase in overweight and obesity mirrors secular trends in adolescent weight status found in the USA during the 1980s and 1990s in the US NHANES (National Health and Nutrition Examination Survey) studies. ${ }^{23}$ Similarly, trends in dyslipidaemia found in our study were similar to findings from the Princeton School study, Bogalusa Heart study and Minneapolis Blood Pressure study. The Princeton study also reported a higher prevalence in hypercholesterolaemia (8-14.8\%) in the study participants from 1975 to $1990 .^{24}$ Likewise, studies carried out in North Indian and Greek populations have shown similar trends in weight status and dyslipidaemia. ${ }^{25}$ The North Indian study reported a decline in HDL-C levels for boys $(-4.6 \mathrm{mg} / \mathrm{dL})$ and a smaller non-significant difference in girls. ${ }^{26}$ Greek school-aged boys were found to have higher mean TC (5.8 mg/dL) and TGs (10.8 mg/dL), and lower HDL-C $(-16.9 \mathrm{mg} / \mathrm{dL}) .^{25}$ The increase in abnormal lipid statuses in children with rising childhood obesity corresponds with epidemiological evidence of obesitycaused dyslipidaemia and mechanisms of the obesitydyslipidaemia linkage. ${ }^{27}$

Secular trends in weight status have varied widely among different countries. A study of 18-year-old boys in Austria also reported a decrease in TC level and increase in TGs despite an increased prevalence of overweight (13.3-15.7\%) and obesity (2.6-5.4\%) between 1986 and $2005 .^{28}$ An even larger trend in decreased cholesterol level was also reported in Finland and Swedish adolescents. $^{29} 30$ Several studies have cited physical activity as an important factor for determining abnormal lipid status. A Welsh study that compared the cardiovascular risk factors in 12-13-year-olds, between 2002 and 2007, found improvements in mean lipid concentrations in both sexes. No change in dietary habits was reported, but there was a significant increase in physical activity. ${ }^{31}$

Our results showed that overweight children faced a higher risk of dyslipidaemia and low HDL dyslipidaemia than those at normal weight. Overweight boys also faced a higher risk of hypertriglyceridaemia than normal weight boys. Several studies reported similar associations between weight status and lipid levels in adolescents. In a study on Korean male adolescents divided into three groups according to BMI tertiles, Kim et al reported that the heaviest group showed the highest levels of abnormal lipid statuses. ${ }^{32}$ Christian et al also reported an OR of 3.0 for obese men and 2.9 for obese women for low HDL dyslipidaemia from the US NHANES 2005-2008 study. ${ }^{33}$ The same study also found elevated risk for hypertriglyceridaemia with an even higher OR of 8.2 and 13.4 for boys and girls, respectively. In a Chinese study, with cut-offs determined by WC, overweight $(>75-$ 90 th centile) and obese ( $>90$ th centile) adolescents had an OR of 1.7 and 3.8, respectively, for dyslipidaemia. ${ }^{34}$

It has also been reported that directly measured body fat percentage was associated with lipid concentrations in adolescents in the USA. The $\beta$ coefficients of linear regression models for TC, HDL-C and TGs were 0.94, -0.45 and 1.02 , respectively, for boys, and $0.55,-0.45$ and 1.01, respectively, for girls. However, Lamb et al note that body fat percentage accounted for $2-20 \%$ of the variation in lipid concentrations, suggesting family history and pubertal status as other factors that might influence lipid concentrations in youths. ${ }^{35}$

BMI and WC are indirect measurements of body fat that are more convenient methods to screen for dyslipidaemia in adolescents. Our results showed BMI and WC statistically elevated the risk of hypertriglyceridaemia, low HDL-C dyslipidaemia and dyslipidaemia. Per unit BMI or WC increase, each abnormal blood lipid status was more strongly associated with increases in BMI. For the unit increment in BMI, the OR for hypertriglyceridaemia was 1.29 and 1.07 for boys and girls, respectively. For low HDL-C dyslipidaemia, the OR was 1.13 and 1.25 for boys and girls, respectively. Boys had a higher association between each unit increase in BMI and dyslipidaemia, with an OR of 1.13, whereas the OR for girls was 1.06. Another study on adolescents in the USA reported an association between BMI-determined obesity and TG/HDL ratio $(r=0.18) .{ }^{36}$ However, other studies have pointed out that WC within BMI category was better than BMI alone in identifying individuals with higher levels of abdominal fat, and may identify normal or overweight BMI individuals with CVD risk factors. ${ }^{34} 37$ This should be taken into consideration as a possible approach to screening dyslipidaemia in adolescents.

In order to prevent or mitigate the increasing trend of dyslipidaemia in the future, we recommend an early screening prevention programme for high risk, overweight and obese individuals, followed by a populationbased intervention programme. ${ }^{38}$ Identification of children and adolescents at a high risk of CVD includes general assessments provided by paediatric care providers and parents and screening for risk assessments such as lipids and lipoprotein levels, BP, body size and family history. These risk interventions include dietary, behavioural and pharmacological approaches, which are key factors in the prevention of dyslipidaemia among children and adolescents. ${ }^{39} 40$

In summary, our analyses of cross-sectional survey from 1996 to 2006 data from the Taipei Children Heart Studies showed an increase in mean weight and BMI in adolescent boys, and dyslipidaemia prevalence in both sexes. The data also showed an increased risk of 
dyslipidaemia in overweight children compared with normal weight children. A significant association between BMI and dyslipidaemia was noted. However, further studies are warranted to elucidate how dyslipidaemia, obesity and health behaviours have changed over time in Taiwan. We predict that this trend will be seen again if conducted in the future, such as in 2016, due to the current diet and lifestyle habits of children. We recommend that screening for obese adolescents would be an ideal tool to develop an intervention programme for obesity-related comorbidities in the future. We believe that health education, healthy eating behaviours and physical activity programmes will result in successful intervention programmes.

\section{Author affiliations}

${ }^{1}$ University of Illinois at Chicago, Chicago, Illinois, USA

${ }^{2}$ National Defense Medical Center, Taipei, Taiwan

${ }^{3}$ Keck School of Medicine of University of Southern California, Los Angeles, California, USA

${ }^{4}$ National Taipei University of Education, Taipei, Taiwan

${ }^{5}$ Department of Dietetics, Taipei Medical University Hospital, Taipei Medical University, Taipei, Taiwan

${ }^{6}$ Tai-tung Hospital, Ministry of Health and Welfare, Taitung, Taiwan

${ }^{7}$ School of Public Health, National Defense Medical Center, Taipei, Taiwan

${ }^{8}$ National Defense Medical Center, School of Public Health, Taipei, Taiwan

Funding This research received no specific grant from any funding agency in the public, commercial or not-for-profit sectors.

Competing interests None.

Patient consent Obtained.

Ethics approval The Ethical Committee of the Scientific Institute approved these surveys. Institutional Review Board (IRB), National Defense Medical Center (NDMC), Taipei.

Provenance and peer review Not commissioned; externally peer reviewed.

Data sharing statement No additional data are available.

Open Access This is an Open Access article distributed in accordance with the Creative Commons Attribution Non Commercial (CC BY-NC 3.0) license, which permits others to distribute, remix, adapt, build upon this work noncommercially, and license their derivative works on different terms, provided the original work is properly cited and the use is non-commercial. See: http:// creativecommons.org/licenses/by-nc/3.0/

\section{REFERENCES}

1. World Health Organization. Cardiovascular diseases (CVDs). In: World Health Organization. Retrieved 24 June 2013, March, 2013. http://www.who.int/mediacentre/factsheets/fs317/en/index.html

2. Wilson PW, Castelli WP, Kannel W B. Coronary risk prediction in adults (the Framingham Heart Study). Am J Cardiol 1987;59:G91-4.

3. McGill HC Jr, McMahan CA, Herderick EE, et al. Origin of atherosclerosis in childhood and adolescence1-4. Am J Clin Nutr 2000;72:1307S-15S.

4. Kavey RW, Daniels SR, Lauer RM, et al. American Heart Association guidelines for primary prevention in atherosclerotic cardiovascular disease beginning in childhood. Circulation 2003;107:1562-6.

5. Chiolero A, Cachat F, Burnier M, et al. Prevalence of hypertension in schoolchildren based on repeated measurements and association with overweight. J Hypertens 2007;25:2209-17.

6. Freedman DS, Mei Z, Srinivasan SR, et al. Cardiovascular risk factors and excess adiposity among overweight children and adolescents: the Bogalusa Heart Study. J Pediatr 2007;150:12-17.

7. Han JC, Lawlor DA, Kimm S. Childhood obesity. Lancet 2010;375:1737-48.
8. Sorof JM, Lai D, Turner J, et al. Overweight, ethnicity, and the prevalence of hypertension in school-aged children. Pediatrics 2004;113:475-82.

9. Ford ES, Capewell S. Coronary heart disease mortality among young adults in the US from 1980 through 2002: concealed leveling of mortality rates. J Am Coll Cardiol 2007:50:2128-32.

10. Department of Health. The Executive Yuan, ROC. The national nutritional guide book. vol 2. Taipei, Taiwan: Taiwan Government, 1991

11. Department of Health, The Executive Yuan, ROC. 2011 statistics of causes of death. In: Department of Health: 2013. Retrieved 24 June 2013, 2012. http://www.doh.gov.tw/EN2006/DM/DM2.aspx?now_ fod list no $=12402 \&$ class no $=390 \&$ level no $=2$

12. Department of Health, the Executive Yuan, ROC. Public health in Taiwan area, Republic of China, 1991. Taipei, Taiwan: Taiwan Government, 1991

13. Lin YC, Yen LL, Chen SY, et al. Prevalence of overweight and obesity and its associated factors: findings from National Nutritional and Health Survey in Taiwan, 1993-1996. Prev Med 37:233-41.

14. Lin YM, Chu CL, Hong CL, et al. Assessment of nutritional status of the youth in Taiwan (1) body height and body weight. J Chin Nutr Soc $1985 ; 10: 91-105$

15. Chu NF. Prevalence and trends of obesity among school children in Taiwan—the Taipei Children Heart Study. Int J Obes 2001;25:170-6.

16. Harchaoui KEL, Visser ME, Kastelein JJP, et al. Triglycerides and cardiovascular risk. Curr Cardiol Rev 2009;5:216.

17. Hokanson JE, Austin MA. Plasma triglyceride level is a risk factor for cardiovascular disease independent of high-density lipoprotein cholesterol level: a meta-analysis of population-based prospective studies. J Cardiovasc Risk 1996;3:213-19.

18. Frontini MG, Srinivasan $\mathrm{SR}, \mathrm{Xu} \mathrm{JH}$, et al. Utility of non-high-density lipoprotein cholesterol versus other lipoprotein measures in detecting subclinical atherosclerosis in young adults (The Bogalusa Heart Study). Am J Cardiol 2007;100:64-8.

19. Kadish $A H$, Litle RL, Sternberg JC. A new and rapid method for determination of glucose by measurement of rate of oxygen consumption. Clin Chem 1968;14:116-31.

20. Richmond W. Preparation and properties of a cholesterol oxidase from Nocardia sp. And its application to the enzymatic assay of total cholesterol in serum. Clin Chem 1973;19:1350-6.

21. Stavropoulos WS, Crouch RD. A new colorimetric procedure for the determination of serum triglyceride. Clin Chem 1974;20:857.

22. Warnick GR, Benderson J, Albers JJ. Dextran sulfate-Mg 2+ precipitation procedure for quantification of high density lipoprotein cholesterol. Clin Chem 1982;28:1379-88.

23. WHO expert consultation. Appropriate body-mass index for Asian populations and its implications for policy and intervention strategies. Lancet 2004;363:157-63.

24. Deurenberg P, Deurenberg-Yap M, Guricci S. Asians are different from Caucasians and from each other in their body mass index/body fat per cent relationship. Obes Rev 2002;3:141-6.

25. Pan W, Flegal KM, Chang $\mathrm{H}$, et al. Body mass index and obesity-related metabolic disorders in Taiwanese and US whites and blacks: implications for definitions of overweight and obesity for Asians. Am J Clin Nutr 2004;79:31-9.

26. Wulan SN, Westerterp KR, Plasqui G. Ethnic differences in body composition and the associated metabolic profile: a comparative study between Asians and Caucasians. Maturitas 2010;65:315-19.

27. Shiwaku K, Anuurad E, Enkhmaa B, et al. Appropriate BMI for Asian populations. Lancet 2004;363:1077.

28. Shirtcliff EA, Dahl RE, Pollak SD. Pubertal development: correspondence between hormonal and physical development. Child Dev 2009;80:327-37.

29. Ogden CL, Flegal KM, Carroll MD, et al. Prevalence and trends in overweight among US children and adolescents, 1999-2000. JAMA 2002;288:1728-32.

30. Eisenmann JC. Secular trends in variables associated with the metabolic syndrome of North American children and adolescents: a review and synthesis. Am J Hum Biol 2003;15:786-94.

31. Singhal N, Misra A, Shah $P$, et al. Secular trends in obesity, regional adiposity and metabolic parameters among Asian Indian adolescents in north India: a comparative data analysis of two selective samples 5 years apart $(2003,2008)$. Ann Nutr Metab 2010;56:176-81.

32. Kim ES, Park JH, Lee MK, et al. Associations between Fatness, Fitness, IGF and IMT among Obese Korean Male Adolescents. Diabetes Metab J 2011;35:610-8.

33. Christian JB, Bourgeois NE, Lowe KA. Prevalence, clinical characteristics and treatment patterns of low high-density lipoprotein cholesterol in the US population: National Health and Nutrition Examination Survey 2005-2008. J Cardiovasc Med (Hagerstown) 2011;12:714-22. 
34. Ma GS, Ji CY, Ma J, et al. Waist circumference reference values for screening cardiovascular risk factors in Chinese children and adolescents. Biomed Environ Sci 2010;23:21-31.

35. Lamb MM, Ogden CL, Carroll MD, et al. Association of body fat percentage with lipid concentrations in children and adolescents: United States, 1999-2004. Am J Clin Nutr 2011;94:877-83.

36. Song Y, Park MJ, Paik HY, et al. Secular trends in dietary patterns and obesity-related risk factors in Korean adolescents aged 10-19 years. Int J Obes 2009;34:48-56.

37. Wang Y, Monteiro C, Popkin BM. Trends of obesity and underweight in older children and adolescents in the United States, Brazil, China, and Russia. Am J Clin Nutr 2002;75:971-7.
38. Hsieh P, FitzGerald M. Childhood obesity in Taiwan: review of the Taiwanese literature. Nurs Health Sci 2005;7:134-42.

39. Lau DCW, Douketis JD, Morrison KM, et al. Canadian clinical practice guidelines on the management and prevention of obesity in adults and children. Can Med Assoc J 2006;176:S1-13.

40. Australian National Health and Medical Research Council. Clinical practice guidelines for the management of overweight and obesity in children and adolescents. In: Canberra, Commonwealth of Australia: Australian National Health and Medical Research Council. Retrieved 24 April 2013, 2003. http://www.health.gov.au/internet/main/ publishing.nsf/Content/893169B10DD846FCCA256F190003BADA/ \$File/children.pdf 